\title{
Controller Design for Closed Loop Speed Control of BLDC Motor
}

\author{
Brajesh Kumar, Subrat Kumar Swain and Dr. Nirbhar Neogi \\ Department of Electrical and Electronics Engineering \\ Birla Institute of Technology, Mesra Ranchi-835215, India \\ brajesh647@yahoo.com, swain.subrat01@gmail.com and nirbharneogi@gmail.com
}

\begin{abstract}
This Paper presents a framework to carry out a simulation for closed loop speed control of BLDC motor with PID and Modified PID controller. The novelty of this paper lies in the design of modified PID controller to track the reference trajectory with and without load in addition to minimizing the initial overshoot. The simulation includes all realistic values and components of the motor. The three phase inverter and its control algorithm is modeled and simulated using MATLAB Simulink. The PID and Modified PID controller track the reference speed with and without load disturbances in closed loop control but the demerit of conventional PID can be observed in its steep overshoot in the closed loop transient response. The speed, torque, dc-link current and back-emf waveforms are analyzed for various load torque conditions through MATLAB Simulink.
\end{abstract}

Keywords: BLDC Motor, PID, Modified PID, VSI, Rise/Settling time, Minimum overshoot, MATLAB.

\section{Introduction}

Recently, the small and medium size motor industries are developing rapidly because of its simple and small structure. The BLDC motor has the advantages of high efficiency, long life time, good speed torque characteristics and high toque to weight ratio compared to DC, Induction and Switched Reluctance motor. It is used in the field of electric drives, aerospace engineering, robotics and household's equipment etc. The paper [1][7][8][12] discusses about the design of conventional and fractional order PID controller for BLDC Motor for closed loop speed control and their performances are compared. Design of Adaptive Neuro-Fuzzy PID controller for AVR system using optimization technique based on SNR-PSO was reported in the literature [2] and the results displayed that the efficiency of SNR-PSO based ANFIS controller is superior than robust PID controller. In the Paper [3], the performance of Induction Motor drive for direct torque and flux control using fuzzy logic and sliding mode speed control was presented and the robustness analysis in presence of parameter uncertainty and load disturbances was carried out. The authors in the paper [4] proposed a novel Proportional Integrator Current Chopping Control (PICCC) method for torque-ripple minimization of Switched Reluctance Generator in presence of load disturbances. Application of Fuzzy logic technique in speed control of doubly fed induction motor using fuzzy PI controller in presence of load torque disturbances is reported in the paper [5]. Application of evolutionary algorithm (Genetic algorithm, Particle Swarm optimization) in designing an optimal controller for motor drives are explored in the literature [6][8][12]. The reference [11] provides an overview of the design of PID and Fuzzy PID controller for BLDC motor and their closed loop responses are compared. The paper [10][12] introduces a concept on the Mathematical modeling and Simulation of the BLDC Motor. The authors in the paper [9] proposed a method to control speed of three phase Induction Motor using Fuzzy PID controller and compared their result with conventional PID in MATLAB/Simulink.

In this paper, the authors have proposed a novel controller design method based on the concept of dominant pole placement for closed loop speed control of BLDC motor. The transient performance obtained from the Modified PID controller is compared

with the responses obtained from conventional PID controller and results demonstrate the superiority of Modified PID controller.

Received: May $29^{\text {th }}, 2016$. Accepted: March $17^{\text {th }}, 2017$ 


\section{Three Phase Inverter Model with 120 degree conduction mode}

Simulating an inverter of a BLDC motor in Simulink uses phase currents, back-EMF, rotor position and dc-source voltage as inputs. Table 1 shows the switching sequences depending upon different rotor position and three phase voltages of the motor.

Table 1. Switching Sequences

\begin{tabular}{|c|c|c|c|c|c|c|c|}
\hline \multirow[b]{2}{*}{ Sequence } & \multicolumn{3}{|c|}{ Rotor position } & \multirow{2}{*}{$\begin{array}{l}\text { Switching } \\
\quad(\mathrm{ON})\end{array}$} & \multicolumn{3}{|c|}{ Phase } \\
\hline & $\mathrm{H}_{\mathrm{a}}$ & $\mathrm{H}_{\mathrm{b}}$ & & & A & $\begin{array}{c}\text { Current } \\
\text { B }\end{array}$ & $\mathrm{C}$ \\
\hline 1 & 1 & 0 & 1 & Sw6, Sw1 & $\mathrm{E}_{\mathrm{dc}}+$ & $\mathrm{E}_{\mathrm{dc}^{-}}$ & OFF \\
\hline 2 & 1 & 0 & 0 & Sw1, Sw2 & $\mathrm{E}_{\mathrm{dc}}+$ & OFF & $\mathrm{E}_{\mathrm{dc}^{-}}$ \\
\hline 3 & 1 & 1 & 0 & Sw2, Sw3 & OFF & $\mathrm{E}_{\mathrm{dc}}+$ & $\mathrm{E}_{\mathrm{dc}^{-}}$ \\
\hline 4 & 0 & 1 & 0 & Sw3, Sw4 & $\mathrm{E}_{\mathrm{dc}^{-}}$ & $\mathrm{E}_{\mathrm{dc}}+$ & OFF \\
\hline 5 & 0 & 1 & 1 & Sw4, Sw5 & $\mathrm{E}_{\mathrm{dc}^{-}}$ & $\mathrm{OFF}$ & $\mathrm{E}_{\mathrm{dc}}+$ \\
\hline 6 & 0 & 0 & 1 & Sw5, Sw6 & OFF & $\mathrm{E}_{\mathrm{dc}^{-}}$ & $\mathrm{E}_{\mathrm{dc}}+$ \\
\hline
\end{tabular}

$\underline{\mathrm{MODE}-1}$ If $\mathrm{H}_{\mathrm{a}}=1, \mathrm{H}_{\mathrm{b}}=0, \mathrm{H}_{\mathrm{c}}=1$ then, $\mathrm{Sw} 1$ and $\mathrm{Sw} 6$ are $\mathrm{ON}$ (previously Sw5 and Sw6 were $\mathrm{ON})$

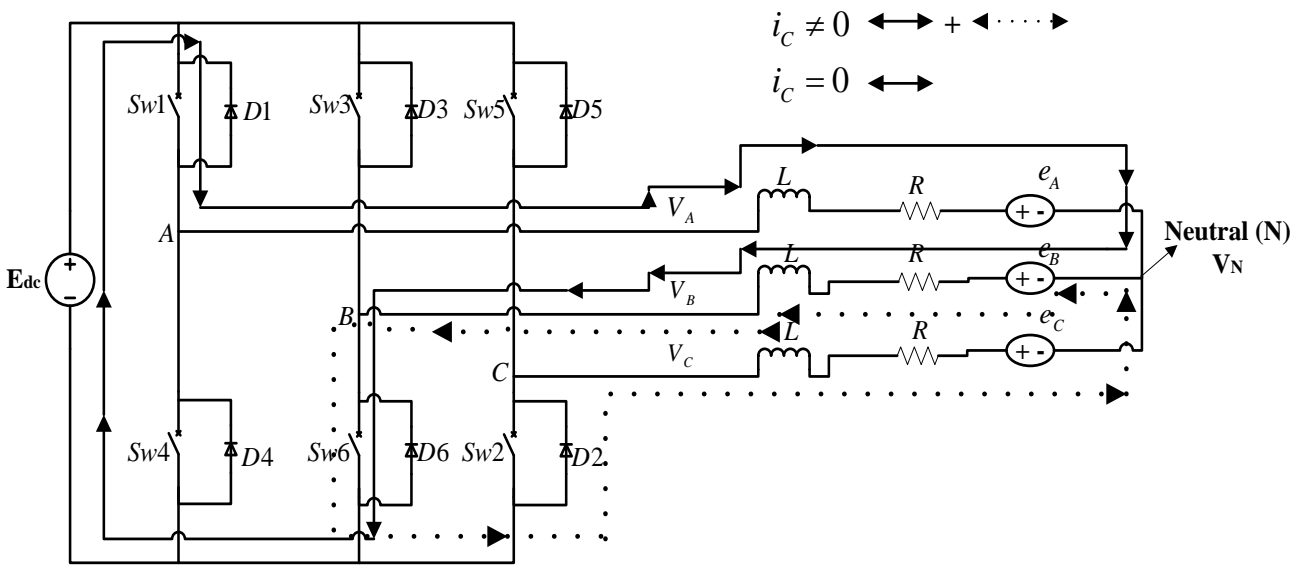

Figure 1. Current path through the three phase inverter for the Mode 1, where the path represented by bold lines with arrows represents the current through the active phase, and the dotted path represent the commutating current from the previous switching sequence.

When $\mathrm{i}_{\mathrm{C}} \neq 0$, the three phase-to-phase voltages can easily be derived from Figure 1.

$$
\begin{aligned}
& V_{A B}=+E_{d c} \\
& V_{B C}=0 \\
& V_{C A}=-E_{d c}
\end{aligned}
$$$$
\text { (3) }\left[\because V_{C A}=-\left(V_{A B}+V_{B C}\right)\right]
$$

where, $\mathrm{V}_{\mathrm{BC}}$ represents the voltage over the reversed biased diode, $\mathrm{D} 2$.

A simplified circuit is shown in Figure 2 for the Mode 1 


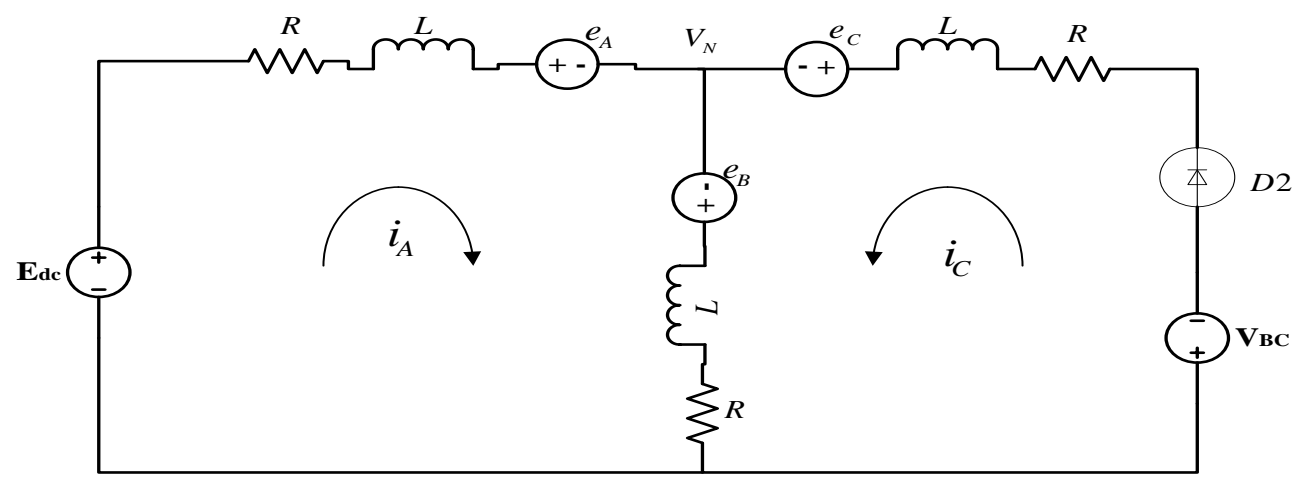

Figure 2. Circuit diagram for Mode 1.

KVL are applied around each mesh in Figure 2 to obtain the three phase to phase voltage, i.e,

$$
\begin{aligned}
& E_{d c}-R i_{A}-L \frac{d i_{A}}{d t}-e_{A}+e_{B}-L \frac{d\left(i_{A}+i_{C}\right)}{d t}-R\left(i_{A}+i_{C}\right)=0-\ldots-(4) \\
& -V_{B C}-R i_{C}-L \frac{d i_{C}}{d t}-e_{C}+e_{B}-L \frac{d\left(i_{A}+i_{C}\right)}{d t}-R\left(i_{A}+i_{C}\right)=0 \ldots-
\end{aligned}
$$

When $i_{C}=0$ and put $i_{A}=i$ in equation (4) and (5), we get

$$
\begin{aligned}
& E_{d c}-2 R i-e_{A}-2 L \frac{d i}{d t}+e_{B}=0 \\
& -V_{B C}-R i-L \frac{d i}{d t}-e_{C}+e_{B}=0
\end{aligned}
$$

Equation (6) and (7) gives

$$
\begin{aligned}
& -V_{B C}-e_{C}+e_{B}+\frac{1}{2}\left[-E_{d c}+e_{A}-e_{B}\right]=0- \\
& \text { Hence, } V_{B C}=\frac{1}{2}\left[-E_{d c}+e_{A}+e_{B}-2 e_{C}\right]
\end{aligned}
$$

So, three phase to phase voltages will be

$$
\begin{aligned}
V_{A B}= & +E_{d c} \\
V_{B C}= & \frac{1}{2}\left[-E_{d c}+e_{A}+e_{B}-2 e_{C}\right] \ldots(10) \\
V_{C A}= & \frac{1}{2}\left[-E_{d c}-e_{A}-e_{B}+2 e_{C}\right]-(12)\left[\because V_{C A}=-\left(V_{A B}+V_{B C}\right)\right]
\end{aligned}
$$

The same derivation is applied for the rest of the switching sequences and results is shown in Table 2.

Table 2. Inverter Output Voltages 
Table 2. Inverter Output Voltages

\begin{tabular}{|c|c|c|c|c|c|c|}
\hline \multicolumn{3}{|c|}{ Rotor position } & \multirow[t]{2}{*}{ Diode current } & \multirow[t]{2}{*}{$V_{A B}$} & \multirow[t]{2}{*}{$V_{B C}$} & \multirow[t]{2}{*}{$\mathrm{V}_{\mathrm{CA}}$} \\
\hline $\mathrm{H}_{4}$ & $\mathrm{H}_{\mathrm{b}}$ & $\mathrm{H}_{\mathrm{c}}$ & & & & \\
\hline 1 & 0 & 1 & $\begin{array}{l}i_{c} \neq 0 \\
i_{c}=0\end{array}$ & $\begin{array}{l}E_{d c} \\
E_{d c}\end{array}$ & $\begin{array}{c}0 \\
\frac{1}{2}\left[-E_{d a}+e_{A}+e_{t h}-2 e_{c}\right]\end{array}$ & $\begin{array}{c}-\mathrm{E}_{\mathrm{dc}} \\
\frac{1}{2}\left[-E_{i x}-e_{A}-e_{n}+2 e_{c}\right]\end{array}$ \\
\hline 1 & 0 & 0 & $\begin{array}{l}i_{11} \neq 0 \\
i_{B}=0\end{array}$ & $\begin{array}{c}0 \\
\frac{1}{2}\left[E_{A}+e_{A}+e_{C}-2 e_{n}\right]\end{array}$ & $\begin{array}{c}\text { Fude } \\
\frac{1}{2}\left[E_{d_{4}}-e_{A}-e_{c}+2 e_{n}\right]\end{array}$ & $\begin{array}{l}- \text { Fde } \\
-E_{d e}\end{array}$ \\
\hline 1 & 1 & 0 & $\begin{array}{l}i_{A} \neq 0 \\
i_{A}=0\end{array}$ & $\begin{array}{c}-\mathrm{E}_{\mathrm{dc}} \\
\frac{1}{2}\left|-E_{d}-e_{n}-e_{c}+2 \varepsilon_{A}\right|\end{array}$ & $\begin{array}{l}E_{d e} \\
E_{d e}\end{array}$ & $\begin{array}{c}0 \\
\frac{1}{2}\left[-E_{\alpha}+\varepsilon_{n}+\varepsilon_{e}-2 e_{A}\right]\end{array}$ \\
\hline 0 & 1 & 0 & $\begin{array}{l}i_{c} \neq 0 \\
i_{c}=0\end{array}$ & $\begin{array}{l}-E_{d c} \\
-E_{d c}\end{array}$ & $\begin{array}{c}0 \\
\frac{1}{2}\left[E_{\omega_{n}}+e_{A}+e_{n}-2 e_{c}\right]\end{array}$ & $\begin{array}{c}E_{d v} \\
\frac{1}{2}\left[E_{d t}-e_{A}-e_{\theta}+2 e_{C}\right]\end{array}$ \\
\hline 0 & 1 & 1 & $\begin{array}{l}i_{B} \neq 0 \\
i_{B}=0\end{array}$ & $\begin{array}{c}0 \\
\frac{1}{2}\left[-E_{d i}+\varepsilon_{C}+e_{A}-2 e_{n}\right]\end{array}$ & $\begin{array}{c}-E_{\mathrm{de}} \\
\frac{1}{2}\left[-E_{d}-\varepsilon_{c}-e_{A}+2 e_{n}\right]\end{array}$ & $\begin{array}{l}E_{d c} \\
E_{d c}\end{array}$ \\
\hline 0 & 0 & 1 & $\begin{array}{l}i_{\wedge} \neq 0 \\
i_{\wedge}=0\end{array}$ & $\frac{1}{\frac{1}{2}\left[E_{d e}-e_{n}-e_{c}+2 e_{A}\right]}$ & $\begin{array}{l}-\mathrm{E}_{\mathrm{dc}} \\
-\mathrm{E}_{\mathrm{dc}}\end{array}$ & $\frac{0}{\frac{1}{2}\left[E_{\Delta L}+e_{n}+e_{c}-2 e_{A}\right]}$ \\
\hline
\end{tabular}

\section{Open Loop Simulation and Result}

Study of electric motor drives system requires the proper selection of a simulation tool. SIMULINK is a toolbox expansion of the MATLAB program. Simulink has the advantages of being capable of complex dynamic system simulations, graphical surrounding with visual real time programming and broad selection of tool boxes. In this section we focus on the Open loop simulation and its result.

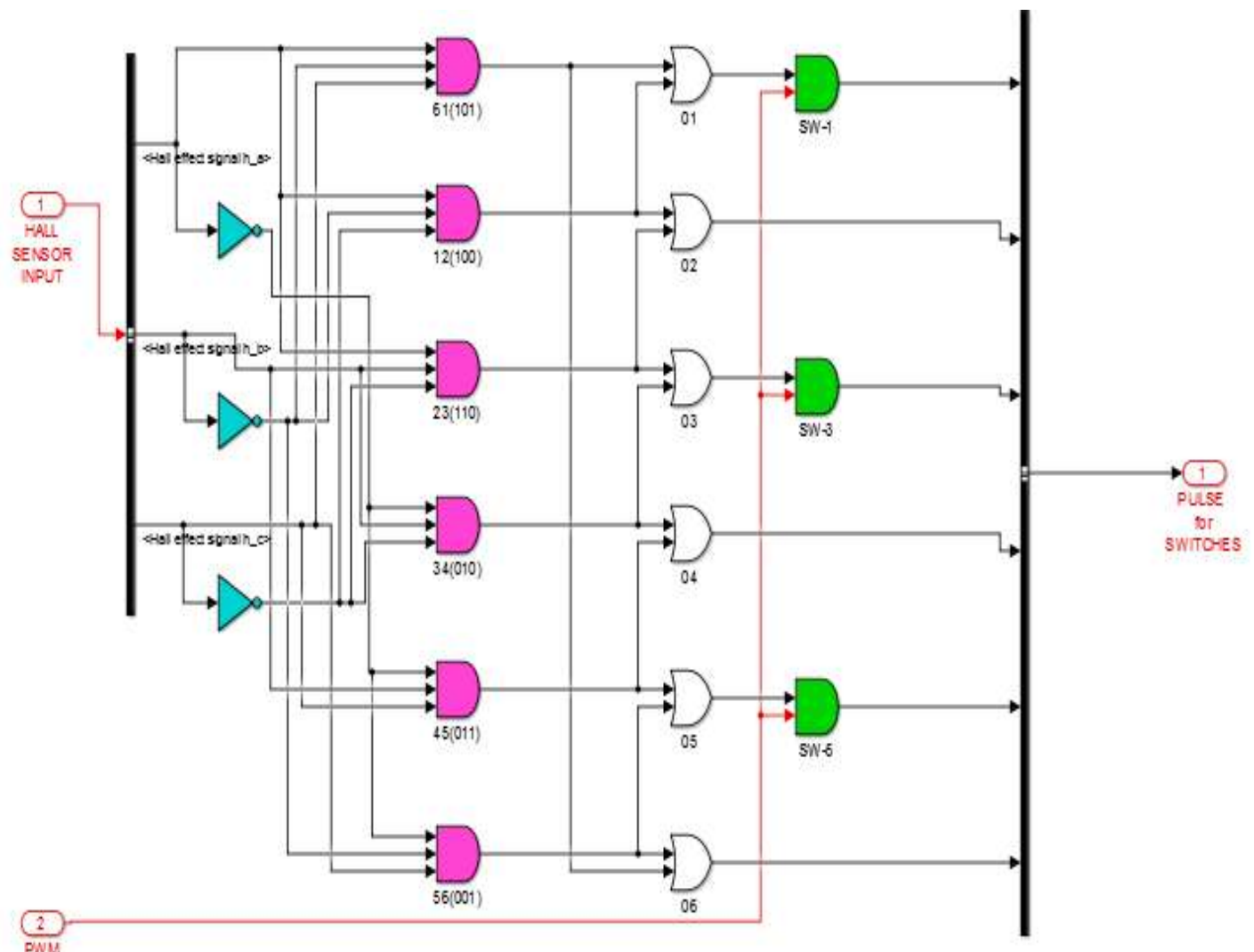

Figure 3. Logic circuit for gate signals. 
Parameters of the BLDC motor considered for simulation:

DC Voltage $=310 \mathrm{~V}$

$\mathrm{RPM}=4600 \mathrm{rpm}(481.7 \mathrm{rad} / \mathrm{sec})$

Moment of Inertia $\mathrm{J}\left(\mathrm{Kgm}^{2}\right)=0.00018$

Resistance Ra (ohm/Phase) $=1.535$

Inductance $\mathrm{La}(\mathrm{mH} / \mathrm{Phase})=3.285$

Poles $(\mathrm{P})=4$

Frequency $(\mathrm{Hz})=50$

The simulink model of logic circuit for gate signals shown in Figure 3, has been developed with the help of rotor position (Hall sensor output) shown in Table 1. Figure 4 and 5 shows the torque and speed v/s time waveform for open loop speed control whereas, Figure 6-8 shows the Back-EMF, Line current and DC-Link v/s time waveform for open loop speed control in presence of disturbances.

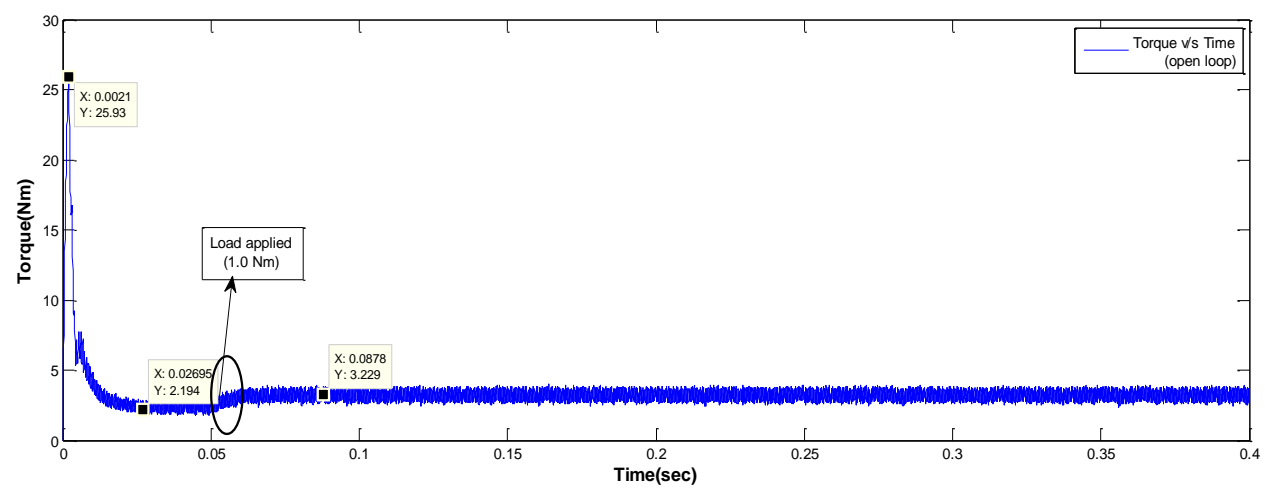

Figure 4. Torque v/s Time waveform for open loop (X-axis represents Time; Y-axis represents Toque in $\mathrm{Nm}$ ).

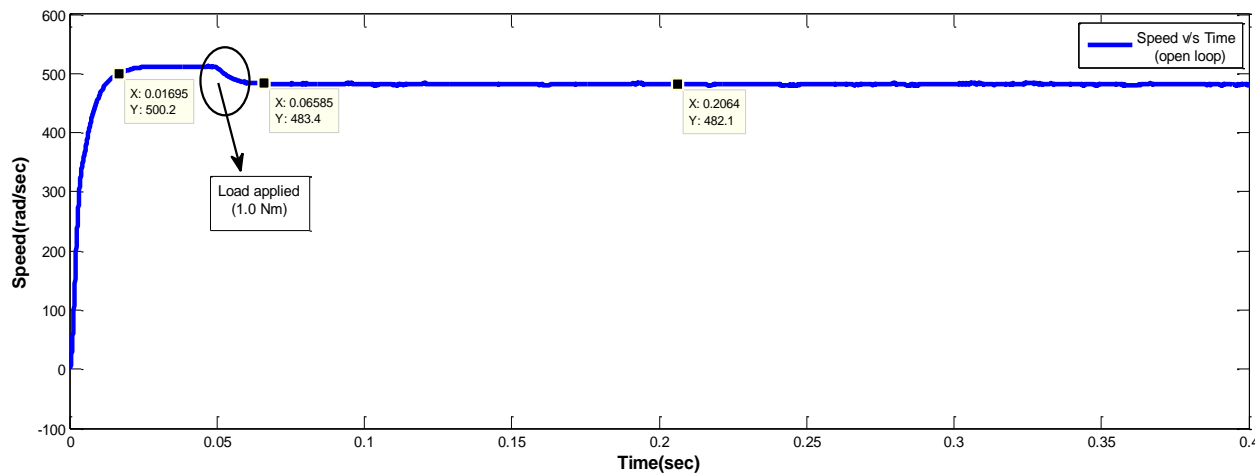

Figure 5. Speed v/s Time waveform for open loop (X-axis represents Time; Y-axis represents Speed in rpm). 


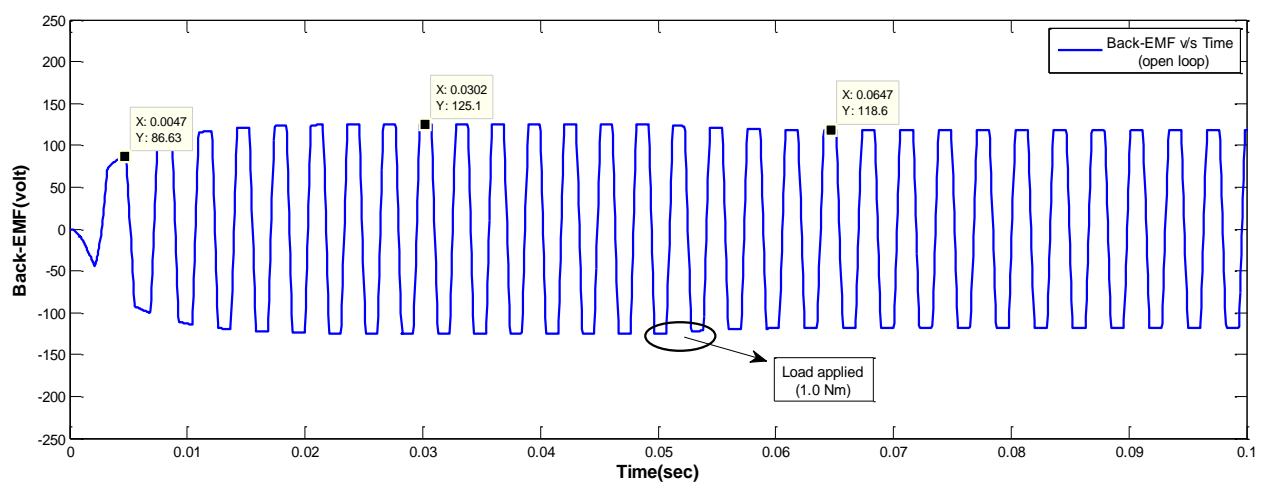

Figure 6. Back-EMF v/s Time waveform for open loop (X-axis represents Time; Y-axis represents Back-EMF in volt).

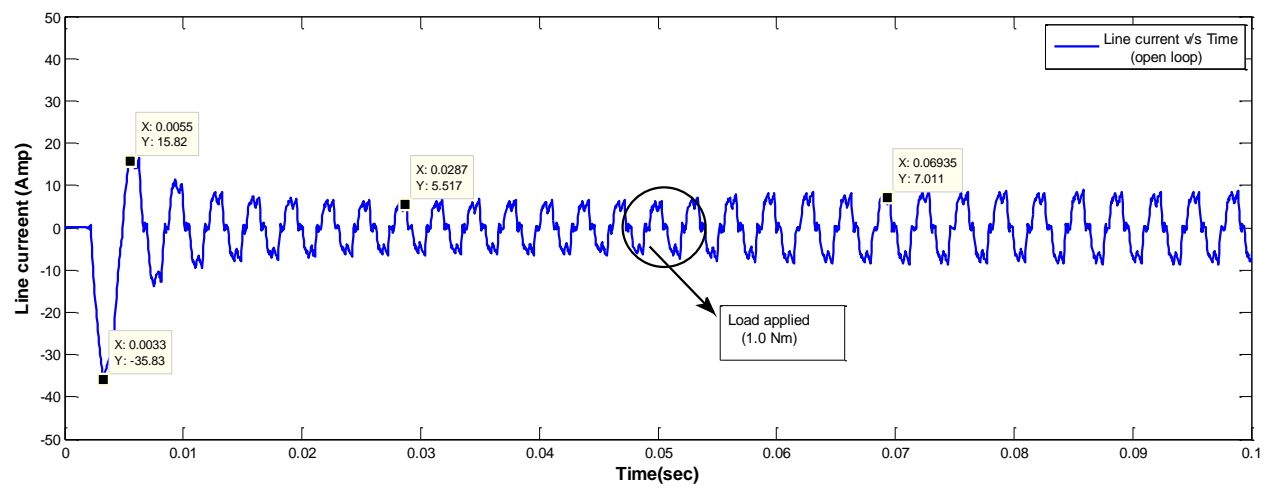

Figure 7. Line Current v/s Time waveform for open loop (X-axis represents Time; Y-axis represents Current in Amp).

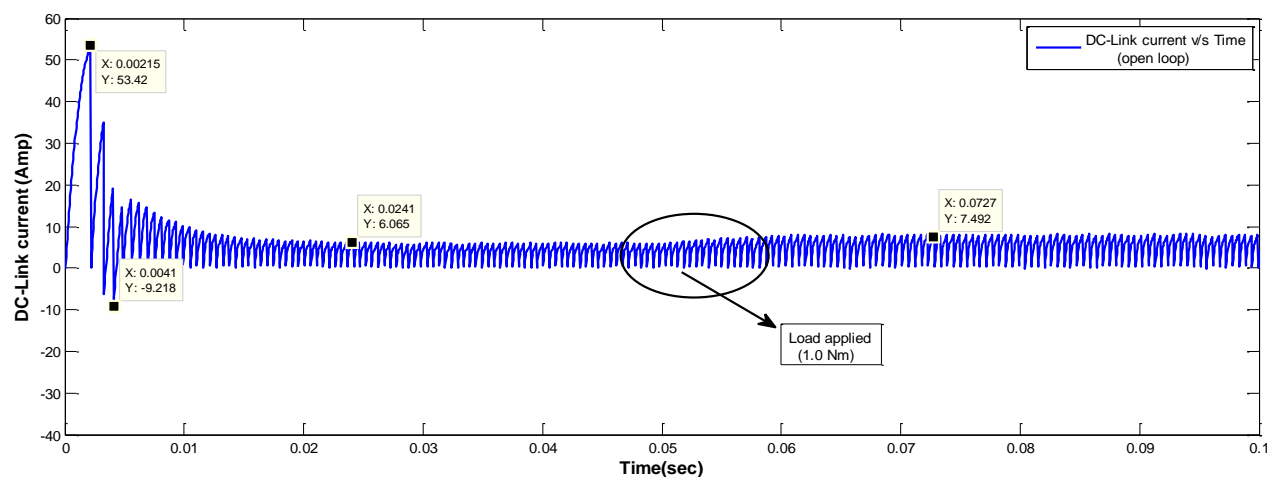

Figure 8. DC-Link Current v/s Time waveform for open loop (X-axis represents Time; Y-axis represents Current in Amp).

From Figure 4 and 5, it can be observed that when load is applied the torque increases and the speed gets reduced but doesn't track the reference speed in case of open loop control. Closed loop control is therefore required for accurate tracking of reference speed in presence of load disturbances. 


\section{Controller Design}

Controller is a device which monitors and alters the operating conditions of a given dynamical system. The control algorithms are usually divided into two main types: Open-loop and Closed-loop.

\section{A. PID Controller}

The PID controller has been widely used in industrial applications owing to its simplicity, robustness, reliability and easy tuning parameters. PID commonly interpreted as Proportional, integral and Derivative controller possesses the following properties:

\begin{tabular}{|l|c|c|c|}
\hline Controller & Response time & Overshoot & Error \\
\hline Proportional (P) & Small & Large & Small \\
\hline Integral (I) & Decrease & Increase & Zero \\
\hline Derivative (D) & Increase & Decrease & Small Change \\
\hline
\end{tabular}

The typical structure of PID control with unity feedback is shown in Figure 9. The

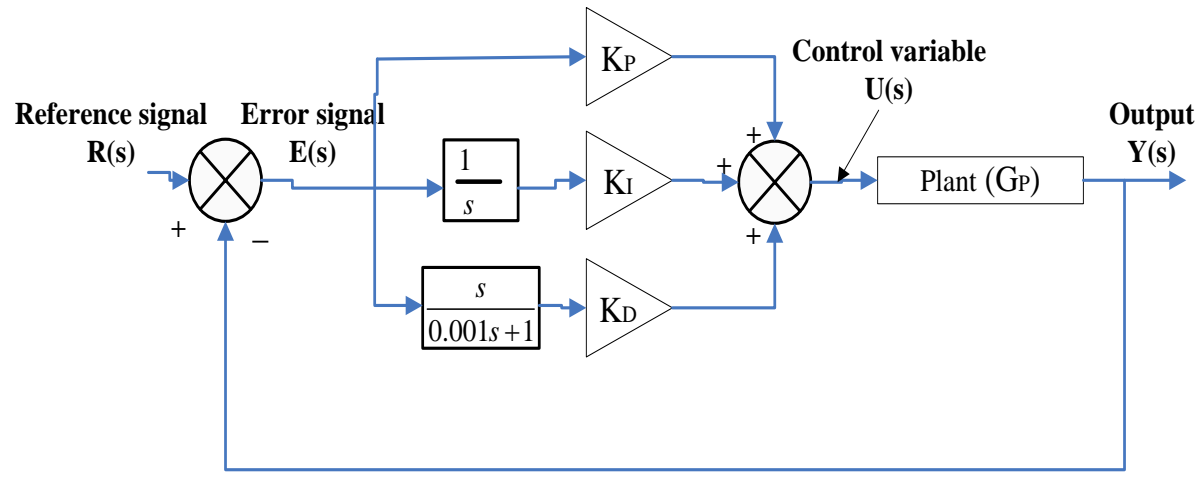

Figure 9: Diagram of a PID control system.

PID controller minimizes the error value by adjusting the control variable, such as Position and Speed etc. The transfer function of the PID controller can be represented as

$$
\begin{aligned}
G_{C(P I D)}(s)=\frac{U(s)}{E(s)}=\left[K_{P}+\frac{K_{I}}{s}+K_{D} s\right] \\
\text { where, } U(s) \text { - Control variable } \\
E(s) \text { - Error signal } \\
K_{P} \quad \text { - Proportional Constant } \\
K_{I} \quad \text { - Integral Constant } \\
K_{D} \quad \text { - Derivative Constant }
\end{aligned}
$$

The closed loop transfer function of the plant (BLDC Motor) with PID controller shown in Figure 9 is 


$$
\left[\frac{Y(s)}{R(s)}\right]_{P I D}=\frac{\left[K_{P}+\frac{K_{I}}{s}+K_{D} s\right] G_{P}(s)}{1+\left[K_{P}+\frac{K_{I}}{s}+K_{D} s\right] G_{P}(s)}
$$

where, $G_{P}(s)$ - Plant transfer function

\section{B. Modified PID Controller}

In this controller, only Integral term is connected in feed forward path and Proportional with Derivative terms is applied to the output of the plant and is fed to the negative part of the comparator of the inner loop. This negative feedback minimizes the initial overshoot that happens in case of conventional PID. The integral term present in the feed forward path helps the system to reach the steady state. This type of response can be considered as little sluggish system without steep overshoots. The typical structure of Modified PID control with unity feedback is shown in Figure 10.

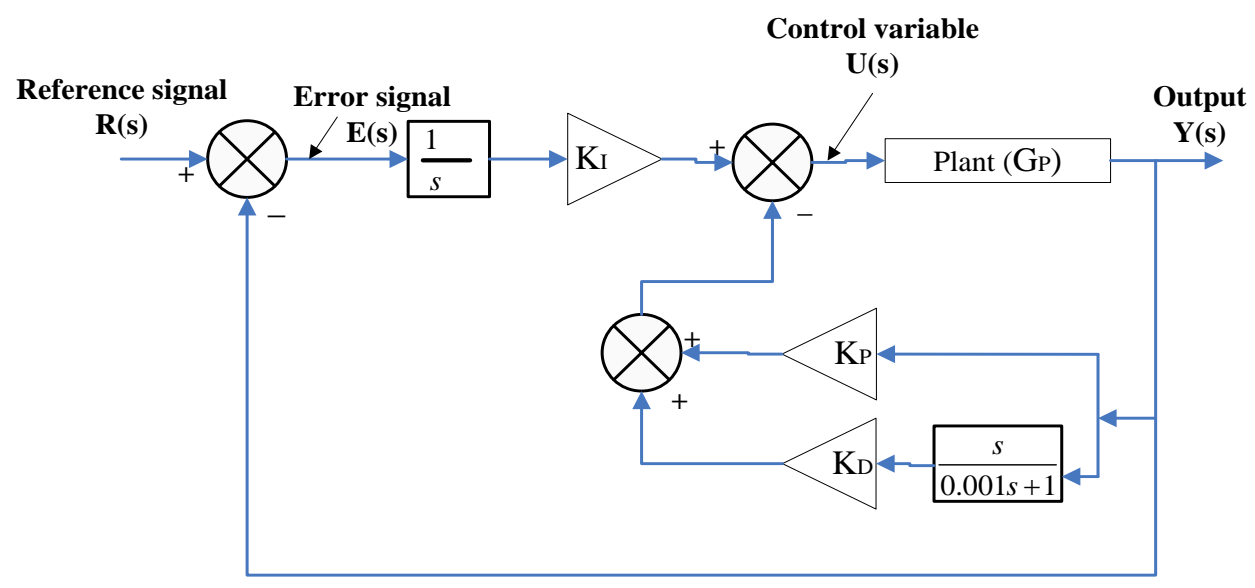

Figure 10. Diagram of a Modified PID control system.

The transfer function of the Modified PID controller can be represented as

$$
G_{C(\text { Modified } P I D)}(s)=\frac{U(s)}{E(s)}=\frac{\frac{K_{I}}{s}}{1+\left[K_{P}+K_{D} s\right] \cdot G_{P}(s)}
$$

The closed loop transfer function of the plant (BLDC Motor) with Modified PID controller shown in Figure 10 is

$$
\left[\frac{Y(s)}{R(s)}\right]_{\text {Modified } P I D}=\frac{\frac{K_{I}}{s} \cdot G_{P}(s)}{1+\left[K_{P}+\frac{K_{I}}{s}+K_{D} s\right] G_{P}(s)}
$$


C. Finalization of $K_{P}, K_{I}$ and $K_{D}$

The transfer function of the Plant (BLDC Motor) is

$$
G_{P}(s)=\frac{\omega(s)}{E_{d c}(s)}=\frac{K_{T}}{\{J \cdot L\} s^{2}+\left\{(J \cdot R)+\left(L . B_{V}\right)\right\} \cdot s+\left\{\left(R . B_{V}\right)+\left(K_{e} \cdot K_{T}\right)\right\}}
$$

where, $J$ - Moment of Inertia $\left(\mathrm{Kgm}^{2}\right)$

$B_{V}$ - Viscous Friction Coefficient $(\mathrm{Nms} / \mathrm{rad})$

$R$ - Resistance ( $\Omega$ /Phase)

$L$ - Inductance (mH/Phase)

$K_{e}$ - Back-EMF Constant (V/Krpm)

$K_{T}$ - Torque Constant $(\mathrm{Nm} / \mathrm{A})$

$\omega$ - Angular Velocity of rotation $(\mathrm{rad} / \mathrm{sec})$

$\mathrm{E}_{\mathrm{dc}}-$ DC-link Voltage $(\mathrm{V})$

The characteristics equation or the denominator of the closed loop transfer function of the system with PID is similar to that of the modified PID controller. So, the value of control parameters (i.e, $\mathrm{Kp}, \mathrm{K}_{\mathrm{I}}$ and $\mathrm{K}_{\mathrm{D}}$ ) will be the same. The characteristics equation will be

$1+G_{C(P I D / \text { Modified PID })}(s) \cdot G_{P}(s) \cdot H(s)=0$

where, $H(s)=1$ (unity feedback)

$$
\begin{gathered}
\quad[J . L] . S^{3}+\left[(J \cdot R)+\left(L \cdot B_{V}\right)+\left(K_{T} \cdot K_{D}\right)\right] \cdot S^{2}+\left[\left(R \cdot B_{V}\right)+\left(K_{T} \cdot K_{e}\right)+\left(K_{T} K_{P}\right)\right] \cdot S+\left[K_{I} K_{T}\right]=0 \\
\therefore S^{3}+\frac{\left[(J \cdot R)+\left(L . B_{V}\right)+\left(K_{T} \cdot K_{D}\right)\right]}{[J . L]} \cdot S^{2}+\frac{\left[\left(R \cdot B_{V}\right)+\left(K_{T} \cdot K_{e}\right)+\left(K_{T} K_{P}\right)\right]}{[J . L]} \cdot S+\frac{\left[K_{I} K_{T}\right]}{[J . L]}=0-(18)
\end{gathered}
$$

Desired specifications for the closed loop control are:

Damping factor $(\zeta)=0.7$

Settling time $(\mathrm{Ts}) \leq 1 \mathrm{sec}$

According to these specification, dominant poles have been found to be at

$\mathrm{S}_{1,2}=-4 \pm 4.0808 \mathrm{i}$

Since, the characteristic equation of the plant with PID and Modified PID controller is of the third order (equation (18)), so the placement of the third pole (a) is quite necessary. According to the dominant pole concept, the third pole can be placed quite far away from the real part of the dominant poles so as to have minimal impact on overall closed loop transient response.

Using pole placement concept, the characteristic equation can be written as

$$
\begin{aligned}
& (S+\alpha) \cdot\left(S^{2}+2 \xi \omega_{n} S+\omega_{n}^{2}\right)=0 \\
& o r, S^{3}+2 \xi \omega_{n} S^{2}+S \omega_{n}^{2}+S^{2} \alpha+2 \xi \omega_{n} \alpha S+\alpha \omega_{n}^{2}=0 \\
& \therefore \quad S^{3}+S^{2}\left(\alpha+2 \xi \omega_{n}\right)+S\left(\omega_{n}^{2}+2 \xi \omega_{n} \alpha\right)+\alpha \omega_{n}^{2}=0
\end{aligned}
$$


Using R-H criteria, the values of KP, KI and $\mathrm{K}$ should be positive. The value of alpha $(\bar{\alpha})$ is taken in such a way that the control parameters should be positive and the value of $\zeta$ should be less than or equal to 1 . Compare and substitute all the motor and control parameters in equation (18) and (20), we obtain

\begin{tabular}{|c|c|}
\hline Parameter & Value \\
\hline $\mathrm{K}_{\mathrm{P}}$ & 0.4638 \\
\hline $\mathrm{K}_{\mathrm{I}}$ & 3.9404 \\
\hline $\mathrm{K}_{\mathrm{D}}$ & 0.1201 \\
\hline
\end{tabular}

The parameters of the controller and the motor are substituted in the closed loop simulink model and responses obtained are discussed in section 5 .

\section{Simulation Result for Closed Loop control of BLDC Motor Drives using PID and Modified PID controller}

The closed loop simulation with PID and Modified PID controller ss carried out employing the following steps:

i) Design Of Three Phase Inverter Using Power MOSFET (IRF 460).

ii) Utilizing the BLDC Motor Parameters in Simulation Available in the Electric Drives laboratory Of BIT Mesra, Ranchi.

iii) The Resultant Speed Values Is Fed Back and Compared with the Reference Speed and the Error generated is fed into the PID/Modified PID Controller.

iv) The Output of the Controller Regulates the Gate Pulse of the Semi converter.

v) The Output of the Semi converter serves as the Dc-Link Voltage for Three Phase VSI.

The torque v/s time, speed v/s time, line current v/s time and voltage v/s time waveform obtained in closed loop simulation with PID and Modified PID controller is shown in Figure $12-17$.

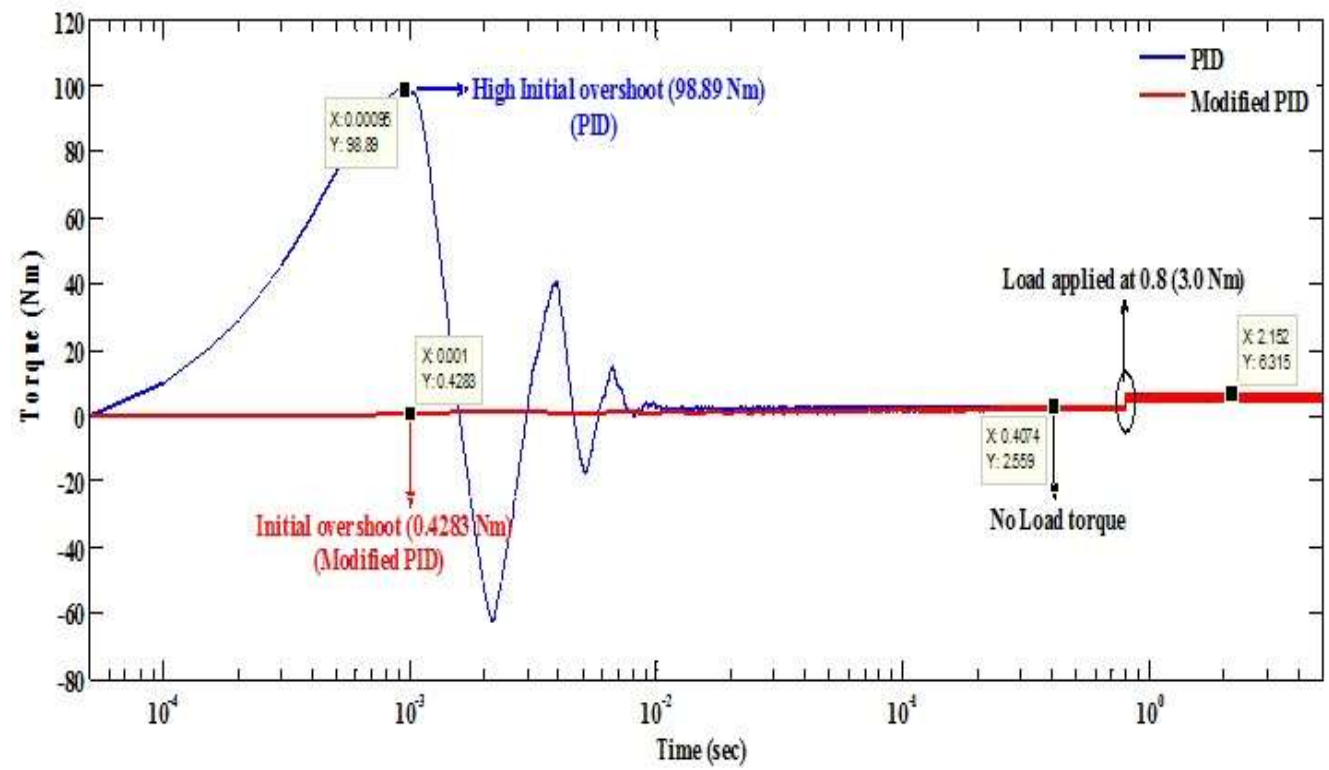

Figure 11. Torque v/s Time waveform for closed loop with initial overshoot (X-axis represents

Time; Y-axis represents Torque (Nm)). 


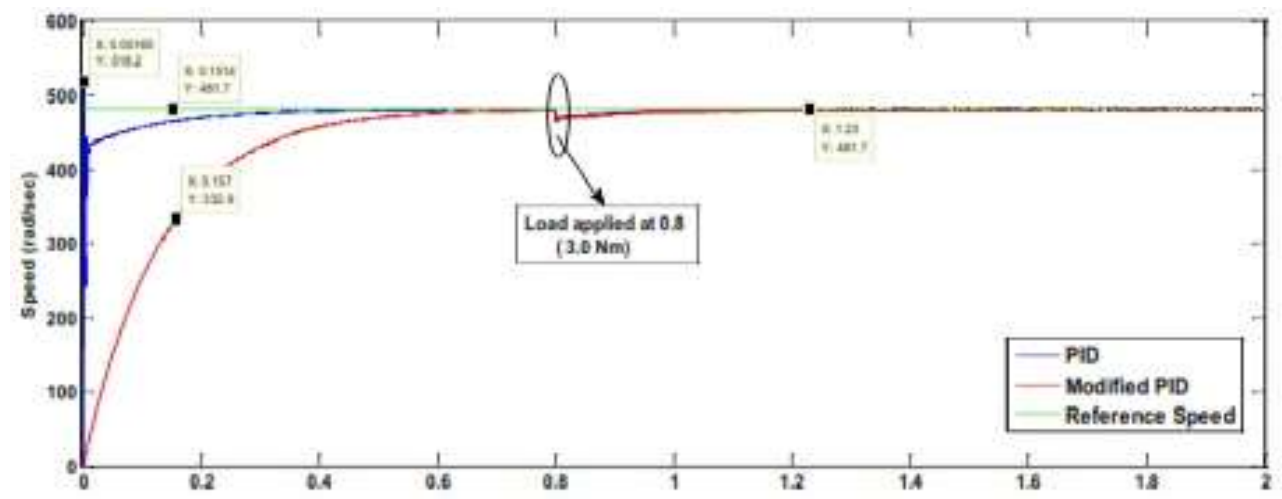

Figure 12. Speed v/s Time waveform for closed loop (X-axis represents Time; Y-axis represents Speed $(\mathrm{rad} / \mathrm{sec}))$.

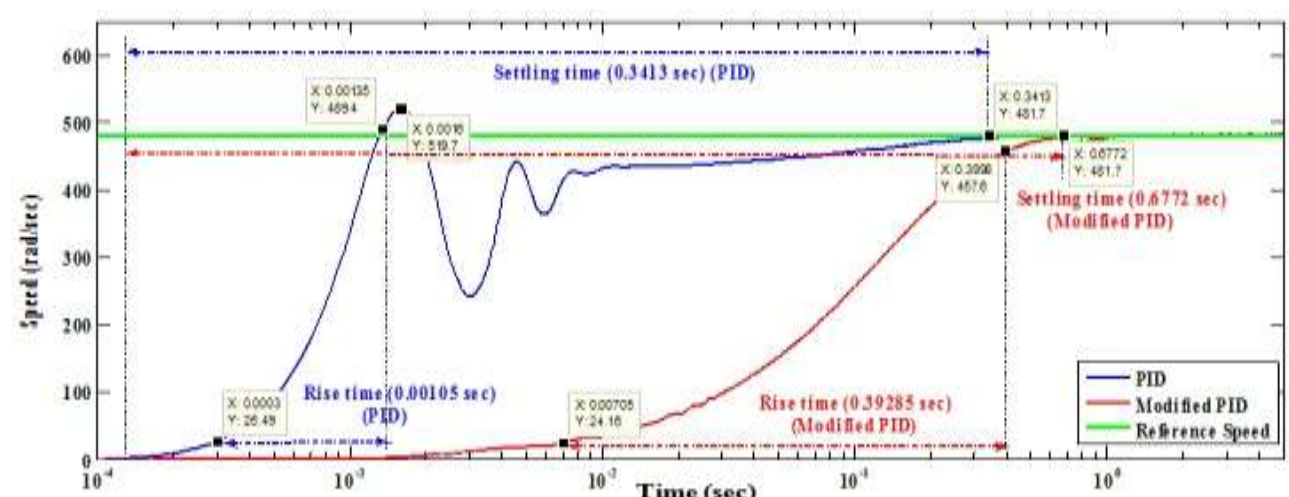

Figure 13. Speed v/s Time waveform for closed loop with rise time and settling time (X-axis represents Time; Y-axis represents Speed $(\mathrm{rad} / \mathrm{sec}))$.

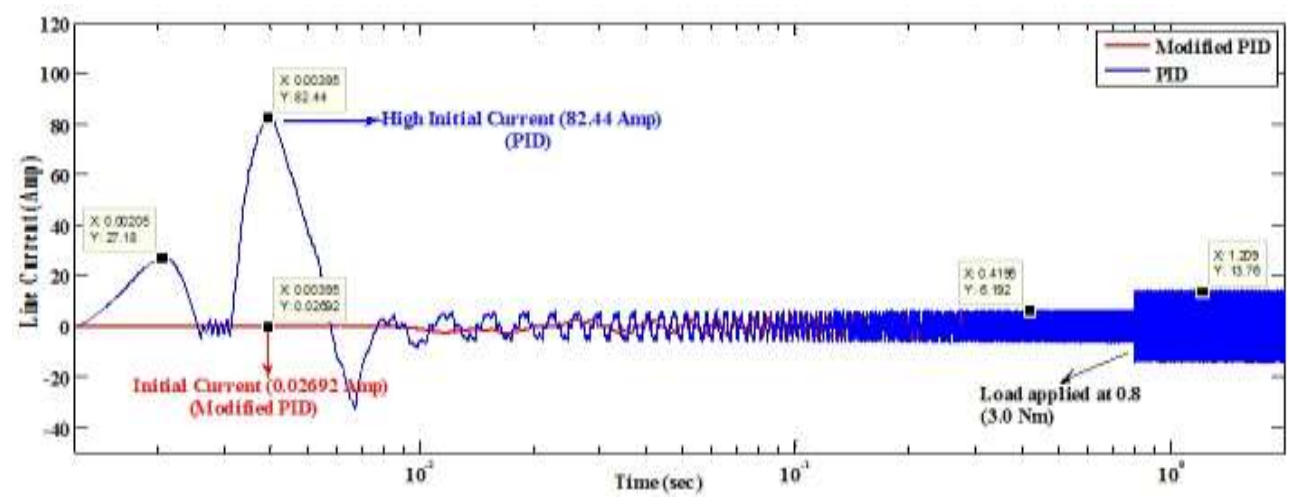

Figure 14. Line Current v/s Time waveform for closed loop (X-axis represents Time; Y-axis represents Current (Amp)). 


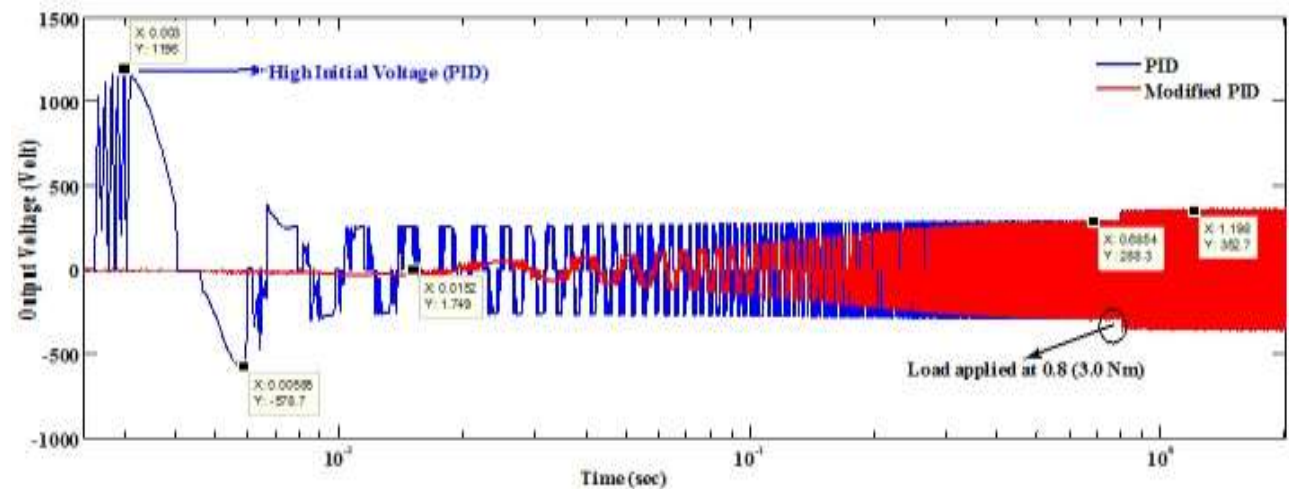

Figure 15. Output Voltage v/s Time waveform for closed loop (X-axis represents Time; Y-axis represents Voltage (volt)).

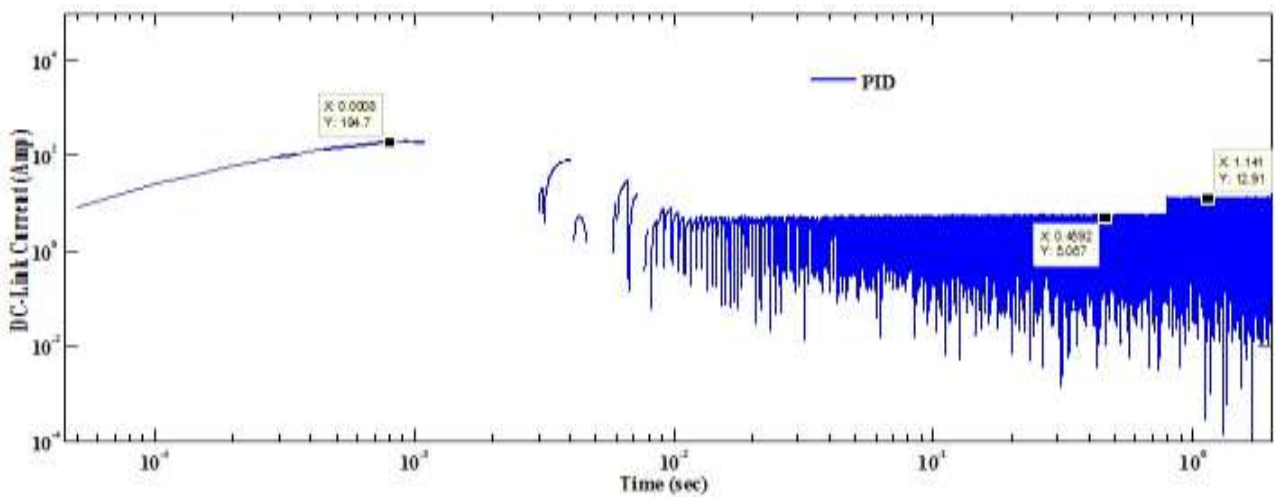

Figure 16. DC-Link Current v/s Time waveform (PID) (X-axis represents Time; Y-axis represents Current (Amp).

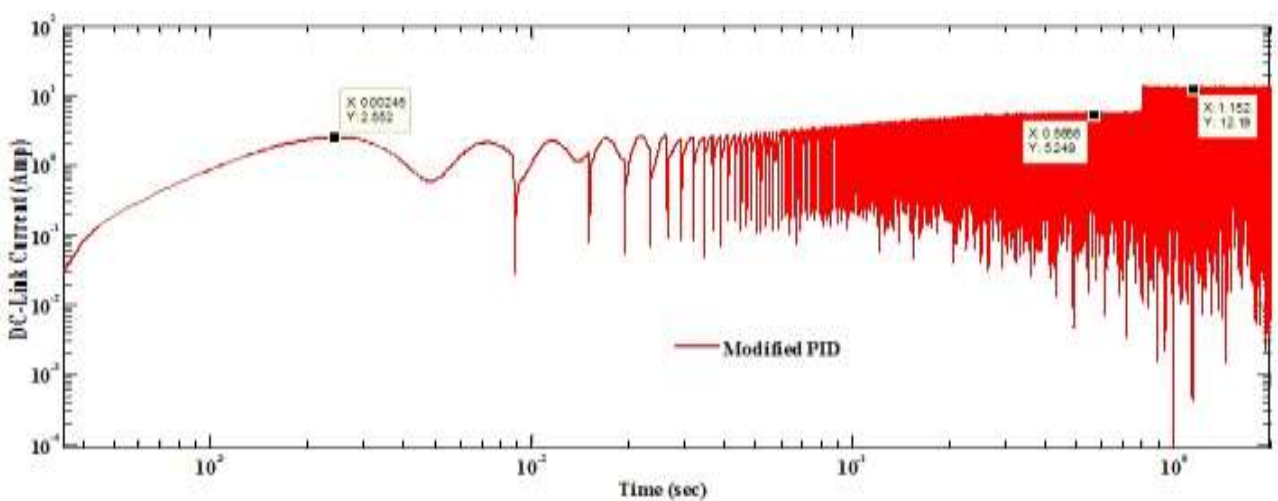

Figure 17. DC-Link Current v/s Time waveform (Modified PID) (X-axis represents Time; Yaxis represents Current (Amp). 
Table 3. Comparison of transient responses of speed with PID and Modified PID Controller

\begin{tabular}{|l|c|c|c|}
\hline Controller Type & Rise Time & Settling Time & Overshoot \\
\hline PID & $0.00105 \mathrm{sec}$ & $0.3413 \mathrm{sec}$ & $7.888 \%$ \\
\hline Modified PID & $0.39285 \mathrm{sec}$ & $0.6772 \mathrm{sec}$ & $0 \%$ \\
\hline Fuzzy PI [14] & - & $1.01 \mathrm{sec}$ & $0 \%$ \\
\hline FOPID [13] & $1.168332 \mathrm{sec}$ & $1.882497 \mathrm{sec}$ & $0 \%$ \\
\hline
\end{tabular}

Table 4. Comparison of Maximum Overshoot in case of PID and Modified PID Controller

\begin{tabular}{|l|c|c|}
\hline Output Parameters & PID (Max. Peak Value) & Modified PID (Max. Peak Value) \\
\hline Torque & $98.89 \mathrm{Nm}$ & $0.4283 \mathrm{Nm}$ \\
\hline Speed & $519.7 \mathrm{rad} / \mathrm{sec}$ & - \\
\hline Line Current & $82.44 \mathrm{~A}$ & $0.02692 \mathrm{~A}$ \\
\hline DC-Link Current & Very high & $2.552 \mathrm{~A}$ \\
\hline
\end{tabular}

From Table 3, it can be observed that overshoot in speed using PID controller is high compared to that of Modified PID. Even if rise time and settling time is better in case of conventional PID, but the fact that overshoot is more overshadows the other transient performance parameters. In Fuzzy, Fuzzy-PI [14] and FOPID [13] controller parameters are computed separately which leads to modification in the assembly of hardware components. In this paper, the controller parameters are not varied for conventional and Modified PID. Thus, for the same set of controller parameters the hardware components can be assembled to examine the transient response characteristics.

Table 4, discusses about the maximum peak values for torque, speed, line current and dclink current with PID and Modified PID controller. From Table 4, it can be observed that the starting torque in case of PID controller is very high. As a result the starting current is high enough to damage the motor winding. Modified PID controller makes the system response little sluggish as the starting torque is comparatively very low. Therefore, the stating current is quite low resulting into safe operation of motor.

\section{Conclusion}

In this paper, a BLDC Motor with three phase inverter has been simulated for 120 degree mode of conduction using Hall sensor. The controllers (PID and Modified PID) are designed and simulated for closed loop operation of BLDC motor. The simulation result indicates that the peak overshoot get reduced when the modified PID controller is used and gives better response in both no load and full load conditions compared to PID controller.

Future Aspect: The Hardware assembly of Open loop has already been implemented and its transient response has been obtained. As far as the closed loop is concerned, the hardware for the PID and Modified PID controller is in progress. Non-linear and advanced controller design methods employing the concepts of sliding mode controller and feedback linearization can be implemented for closed loop speed control. Hardware development of motor and controller configuration can be designed to verify the simulink result.

\section{References}

[1]. Narmada,R.; Arounassalame,M., "Design and performance evaluation of Fractional ORDER controller for Brushless DC Motor" , International Journal on Electrical Engineering and Informatics, vol.6, no.3, pp.606-617, September 2014.

[2]. Yavarian,Kamal; Mohammadian,Amir; Hashmi,Farid, "Adaptive Neuro Fuzzy Inference System PID Controller for AVR System Using SNR-PSO Optimization", International Journal on Electrical Engineering and Informatics, vol.7, no.3, pp.394-408, 9th September 2015.

[3]. Ramesh,Tejavatha; Panda,Kumar,Anup; Kumar,Shiva,S., "Fuzzy Logic and SlidingMode Speed Control Based Direct Torque and Flux Control Scheme to Improve the 
Performance of an Induction Motor Drive", International Journal on Electrical Engineering and Informatics, vol.6, no.1, pp.155-180, 26th March 2014.

[4]. Suthapadmanabhan,S.; Kannan,K., "Closed Loop Control of Excitation Parameters for High Speed Switched Reluctance Generator Using MATLAB/SIMULINK", International Journal on Electrical Engineering and Informatics, vol.2, no.3, pp.232-243, 13th August 2010.

[5]. Ben,Attous,D.; Bekakra,D., "Speed Control of a Doubly Fed Induction Motor using Fuzzy Logic Techniques", International Journal on Electrical Engineering and Informatics, vol.2, no.3, pp.179-191, 8th July 2010.

[6]. Arulmozhiyal,R., Kandiban,R., "Design of Adaptive Fuzzy PID Controller for Speed Control of BLDC Motor", International Journal of Soft Computing and Engineering (IJSCE), vol.2, pp.386-391, March 2012.

[7]. Al-Mashakbeh,Othman,Saleh,Atef, "Proportional Integral and Derivative Control of Brushless DC Motor", European Journal of Scientific Research, pp.198203, 2009.

[8]. Nasri,Mehdi, Nezamabadi-pour,Hossein, MaghFoori,Malihe, "A PSO-Based Optimum Design of PID Controller for a Linear Brushless DC Motor", World Academy of Science, Engineering and Technology, pp.211-215, 26 January 2007.

[9]. Bidwe,Umesh,B., Shinde,Sanjay,M., "Speed Control of Three Phase Induction Motor Using Fuzzy-PID Controller", International Journal of Engineering Research and Technology (IJERT), vol.2, issue 11, pp.3794-3799, November 2013.

[10]. Pillay,Pragsen, Krishnan,Ramu, "Modeling, Simulation and Analysis of Permanent Magnet Motor Drives, Part-II: The Brushless DC Motor Drive", IEEE Transaction on Industry Applications, vol.25, no.2, pp.274-279, March/April 1989.

[11]. Shamseldin,Abdelbar,Mohammed, EL-Samahy,Adel,A., "Speed Control of BLDC Motor By Using PID Control and Self-tuning Fuzzy PID controller", IEEE 15th International Workshop on Research and Education in Mechatronics (REM), Elgouna,Egypt, September 9-11 2014.

[12]. Srikanth,Prof.S., Chandra,Raghu,G., "Modeling and PID Control of the Brushless DC Motor with the help of Genetic Algorithm", IEEE International Conference on Advances in Engineering, Science and Management (ICAESM), pp.639644, March 30-31, 2012.

[13]. Rajasekhar Anguluri, Das Shantanu, Abraham Ajith, "Fractional order PID controller Design for speed control of chopper fed DC motor drive using Artificial Bee Colony Algorithm", IEEE International Conference on 5th World congress on Nature and Biologically Inspired computing(NaBIC), Forgo, North Dakota USA, August 12-14, 2013.

[14]. Tiwary Neha, Rathinam A., Ajitha S., "Design of Hybrid Fuzzy-PI controller for speed control of Brushless DC Motor", IEEE International Conference on ElectronicsCommunication and Instrumentation (ICECI), 2014. 


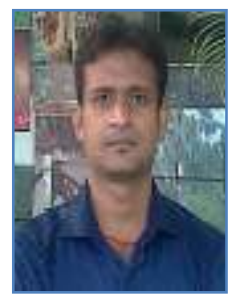

Brajesh Kumar was born in Bihar in the year 1987. He received his Bachelor's degree in Electrical and Electronics Engineering from Pt. Ravishankar Shukla University, Raipur, Chhattisgarh in the year 2008. He received his Master's degree in Power Electronics from Birla Institute of Technology, Mesra, Ranchi, Jharkhand in the year 2016. He has industrial as well as teaching experience. His professional experience includes working with PIL, Champa (C.G.) and BPSL, Jharsuguda (Odisha). His research interest includes Power Electronics, Analog Electronics and Control System.

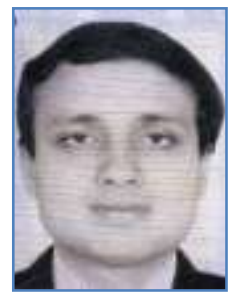

Subrat Kumar Swain was born in Rourkela, Odisha in the year 1983. He received his Bachelor's degree in Electrical Engineering from College of Engineering and Technology, Bhubaneswar, Odisha in the year 2005. He received his dual Master's degree, one in Electrical Engineering from Wayne State University in Michigan, USA, and the other one in Computer Engineering from Arizona State University, USA in the year 2009 and 2013. Currently he is serving as a faculty member in the Department of Electrical and Electronics Engineering at Birla Institute of Technology in Mesra, Ranchi in India. His research interest includes Control theory, design and analysis of Fractional Order Controller for Multivariable Systems. He is currently associated in various professional organizations and is a regular reviewer of ISA transactions.

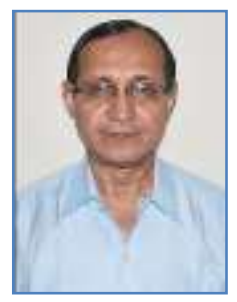

Nirbhar Neogi completed his B.Tech. and M.Tech. from IIT Kharagpur in the year 1972 and 1974 respectively. He received his Ph.D. degree from B.I.T. Mesra, Ranchi in 2015. He had been Executive Director of RDCIS and SSO of SAIL before retiring in Nov' 2010. His professional experience includes working with Larsen \& toubro Ltd, India Foils and Steel Authority of India Ltd. (SAIL). He was a visiting faculty at Birla Institute of Technology, Mesra, Ranchi, India from 2011 till June16. He has co-authored a book and published \& presented many technical papers in Indian and international journals and conferences. He is also co-inventor of three patents. He has been featured in the book "100 Managers in action" by noted management consultant T V Rao. He is a Fellow of the Institute of Engineers, India; life member of Computer Society of India and a Senior member of IEEE, USA. 